\title{
Effect of tourniquet application on cement penetration in primary total knee arthroplasty: a meta-analysis
}

\author{
Shuxin Yao, Weijie Zhang, Jianbing Ma and Jianpeng Wang*
}

\begin{abstract}
Background: Tourniquet application is expected to improve surgery exposure and cementation process in total knee arthroplasty (TKA) but its effectiveness remains controversial and needs to be further explored. The aim of this meta-analysis was to assess the effect of tourniquet in primary TKA. The hypothesis is that the tourniquet application affects the cement penetration in TKA.

Methods: A search was conducted in PubMed, Embase, and the Cochrane Library for the potentially eligible articles. Two independent researchers reviewed the articles retrieved against the pre-designed inclusion and exclusion criteria. In primary TKA, cement penetration was assessed, and the data between the tourniquet-assisted and non-tourniquet-assisted TKAs were compared. Statistical significance was set at $P<0.05$.
\end{abstract}

Results: A total of 4 randomized controlled trials and 3 non-randomized controlled trials (involving 675 patients) were included. There was no significant difference between the tourniquet-assisted and non-tourniquet-assisted TKAs in terms of cement penetration ( $P>0.05)$. There were no significant differences in the total surgical time, blood loss, blood transfusion, the Knee Society Score, and the visual analogue scale (VAS) between the two kinds of procedures $(P>0.05)$.

Conclusions: Tourniquet application may not affect cement penetration in primary TKA and may not help reduce blood loss, ease knee pain or improve the knee function. A surgeon may choose to use a tourniquet or not according to his or her own preference.

Level of Evidence: Level Ib, meta-analysis.

Keywords: Total knee arthroplasty, Tourniquet, Cement, Meta-analysis

\section{Introduction}

Total knee arthroplasty (TKA) represents one of the most common and successful treatment alternatives for end-stage knee osteoarthritis [1]. However, TKA may fail due to a variety of reasons, including knee joint instability, infection, persistent pain, aseptic implant loosening, etc. [2-5]. Aseptic loosening remains the leading cause of early- and late-stage revisions. Currently, whether

\footnotetext{
* Correspondence: 280771976@qq.com

Department of Orthopedics Honghui Hospital, Xi'An Jiaotong University, No.555 East Youyi Road, Shanxi, Xi'an, China
}

tourniquet use in TKA is associated with a risk of aseptic loosening remains controversial.

Aseptic loosening may be associated with individual differences, surgical techniques, and the type of implants used $[4,6]$. The strength of the cement-bone interface is also important for the TKA survivorship and related revision [7-11]. Multiple in vitro and in vivo studies have shown that intraoperative bleeding and high intramedullary pressure during cement penetration might compromise the integrative and shear strength of the bonecement interface [12, 13]. Pfitzner et al. [5] suggested a tourniquet be used in TKA because it provides a

(c) The Author(s). 2021 Open Access This article is licensed under a Creative Commons Attribution 4.0 International License, which permits use, sharing, adaptation, distribution and reproduction in any medium or format, as long as you give

appropriate credit to the original author(s) and the source, provide a link to the Creative Commons licence, and indicate if changes were made. The images or other third party material in this article are included in the article's Creative Commons licence, unless indicated otherwise in a credit line to the material. If material is not included in the article's Creative Commons licence and your intended use is not permitted by statutory regulation or exceeds the permitted use, you will need to obtain permission directly from the copyright holder. To view a copy of this licence, visit http://creativecommons.org/licenses/by/4.0/.
} 
bloodless cement-bone interface, facilitates penetration of cement, improves the quality of cementation and the mechanical interlock with the implant [11]. However, some controversial studies argued that using a tourniquet may not improve cement penetration or fixation but may lead to increased blood loss, more venous thromboembolic issues, and lower functional scores of the knee in the early postoperative period [5, 14-22]. Currently, there is no convincing evidence on the effect of tourniquet on cement penetration, implant loosening, or implant survivorship.

The aim of this meta-analysis was to assess the effect of tourniquet on TKA. The hypothesis was that the tourniquet application affects cement penetration in TKA.

\section{Materials and methods}

\section{Search Strategy}

A meta-analysis was conducted according to the Preferred Reporting Items for Systematic Reviews and Meta-
Analyses (PRISMA statement) guidelines [23]. We systematically searched the electronic databases, including PubMed, Embase, and the Cochrane Library in November 2020. The relevant English-language studies were identified. The search strategy included use of the the following terms: "Arthroplasty, Replacement, Knee", "Tourniquet", "Cement", Boolean operators (AND, OR), and various combinations.

\section{Inclusion and Exclusion Criteria}

The studies were selected against the following inclusion criteria: (1) any study on tourniquet-assisted versus nontourniquet-assisted TKAs; (2) primary TKAs; (3) any report on cement penetration; and (4) research articles published in English. The exclusion criteria included: (1) review articles, case reports, letters, and comments; (2) any study on tourniquet or non-tourniquet alone; (3) cementless TKAs and (4) any report involving no comparison of results.

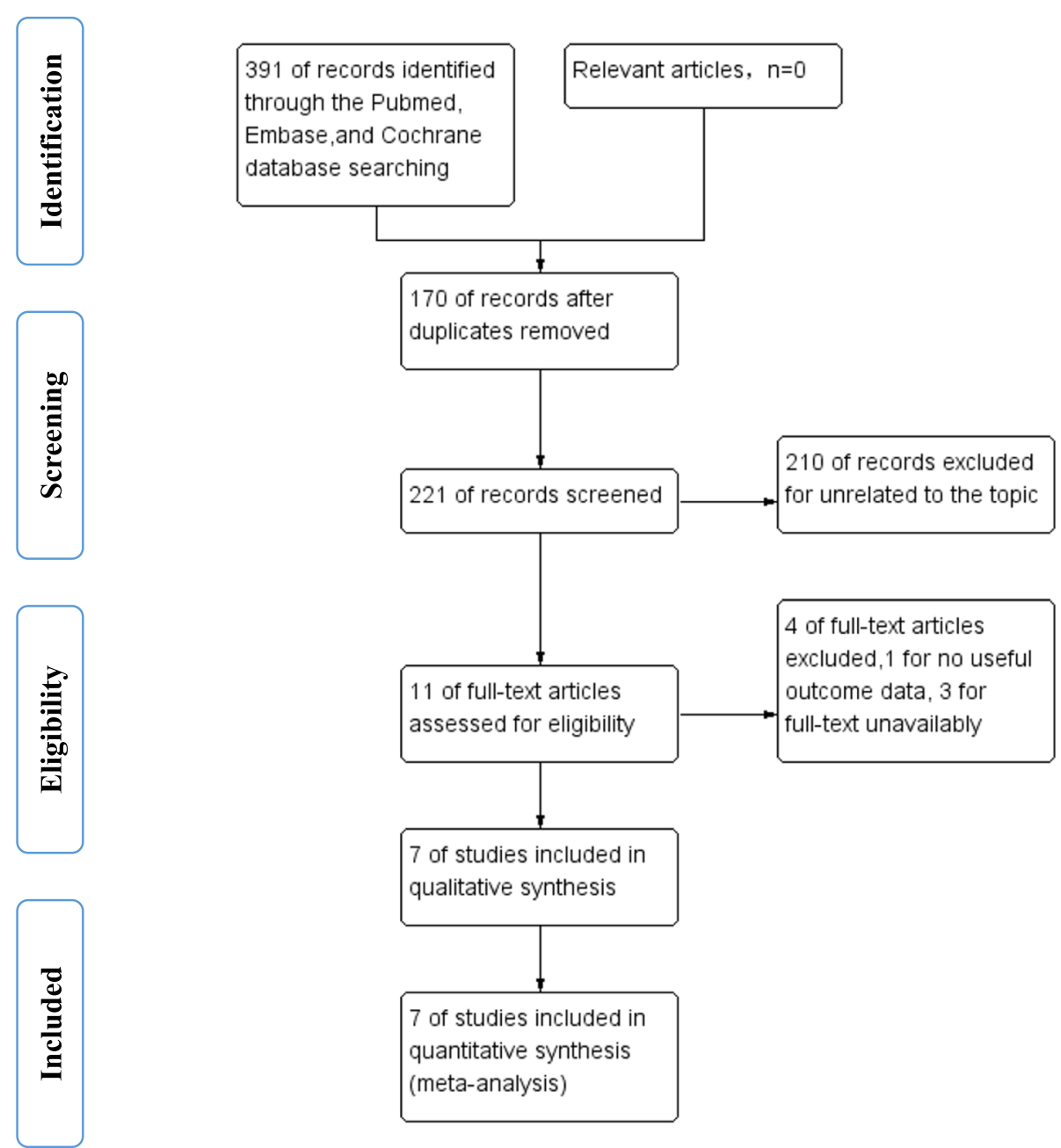

Fig. 1 PRISMA flow diagram describing the selection process for the relevant clinical trials included in this meta-analysis 
Table 1 Characteristics of 7 studies

\begin{tabular}{|c|c|c|c|c|c|c|c|c|c|}
\hline Study & Groups & Patients $(n)$ & $M / F$ & $\begin{array}{l}\text { Mean age } \\
\text { (y) }\end{array}$ & BMI & $\begin{array}{l}\text { Knee } \\
\text { (right/left) }\end{array}$ & Cement (g) & Cement manufacturers & $\begin{array}{l}\text { Tourniquet } \\
\text { pressure } \\
(\mathrm{mmHg})\end{array}$ \\
\hline \multirow[t]{2}{*}{ Pfitzner 2014 [5] } & Tourniquet & 45 & $21 / 24$ & $69.3(47-85)$ & $27.8(18.5-38.1)$ & NA & 40 & Palacos Rं; Heraeus & 350 \\
\hline & Non-tourniquet & 45 & $11 / 34$ & $70.5(50-90)$ & $26(18.5-33.9)$ & NA & & & \\
\hline \multirow[t]{2}{*}{ Vertullo 2017 [14] } & Tourniquet & 20 & $10 / 10$ & $67.85 \pm 6.91$ & $30.43 \pm 5.07$ & $10 / 10$ & 80 & Palacos R + G; Zimmer & 300 \\
\hline & Non-tourniquet & 20 & $11 / 9$ & $65.65 \pm 8.54$ & $31 \pm 5.31$ & $13 / 7$ & & & \\
\hline \multirow[t]{2}{*}{ Ozkunt 2018 [15] } & Tourniquet & 24 & NA & $65.05(52-81)$ & NA & NA & NA & OrCem 3; European Medical & NA \\
\hline & Non-tourniquet & 25 & NA & $65.05(52-81)$ & NA & NA & & & \\
\hline \multirow[t]{2}{*}{ Jawhar 2018 [17] } & Tourniquet & 43 & $16 / 27$ & $70 \pm 6.8$ & $31.9 \pm 5.7$ & $18 / 25$ & 40 & SmartSet; DePuySynthes & 360 \\
\hline & Non-tourniquet & 43 & $16 / 27$ & $71 \pm 6.8$ & $31.9 \pm 5.7$ & $26 / 17$ & & & \\
\hline \multirow[t]{2}{*}{ Touzopoulos 2019 [18] } & Tourniquet & 50 & $42 / 8$ & $70.73 \pm 6.56$ & $31.04 \pm 5.43$ & NA & 20 & Palacos R $+G^{\circ}$; Heraeus & 350 \\
\hline & Non-tourniquet & 50 & $42 / 8$ & $69.92 \pm 6.89$ & $31.12 \pm 3.95$ & NA & & & \\
\hline \multirow[t]{2}{*}{ Herndon 2019 [19] } & Tourniquet & 70 & $28 / 42$ & $67 \pm 9.2$ & NA & NA & 80 & Simplex; Stryker & 250 \\
\hline & Non-tourniquet & 70 & $26 / 44$ & $67.5 \pm 8.3$ & NA & NA & & & \\
\hline \multirow[t]{2}{*}{ Dincel 2020 [20] } & Tourniquet & 74 & $15 / 59$ & $65.34 \pm 7.94$ & $32.83 \pm 5.80$ & $40 / 34$ & NA & Hi-Fatigue; Zimmer Biomet & $150+$ systolic \\
\hline & Non-tourniquet & 96 & $20 / 76$ & $66.12 \pm 8.78$ & $32.72 \pm 5.73$ & $55 / 41$ & & & \\
\hline
\end{tabular}

NA not available; BMI body mass index; $y$ year; $g$ gram

\section{Selection Criteria}

The titles and abstracts of the selected articles were read, and the full text was further reviewed by two independent reviewers. A disagreement was resolved by discussion among all investigators until a final consensus was reached.

\section{Extraction of Data}

All data of the relevant results were recorded. The data of participants included the numbers of knees and patients, demographics (age, gender, body mass index, side, etc.). The primary outcome measure was the cement penetration. Other relevant data, including surgical time, blood loss, blood transfusion, the Knee Society Score (KSS), and the visual analogue scale (VAS), were also extracted.

\section{Assessment of Quality}

Two independent reviewers assessed the quality of the randomized controlled trials (RCTs) using the modified Jadad scale (7-points) on the basis of the Cochrane Handbook for Systematic Reviews of Interventions [24]. The studies that scored greater than 4 points were considered to be of high quality. The quality of the non-randomized studies was assessed on the Newcastle-Ottawa Quality Assessment Scale, which consists of 3 parts, i.e., selection (04 points), comparability ( $0-2$ points), and outcome assessment $(0-3$ points) [25]. The studies that were awarded over 6 points were deemed of high quality.

\section{Statistical Analysis}

Heterogeneity was determined by estimating the proportion of between-study inconsistencies by examining actual differences between studies identified in the data extraction

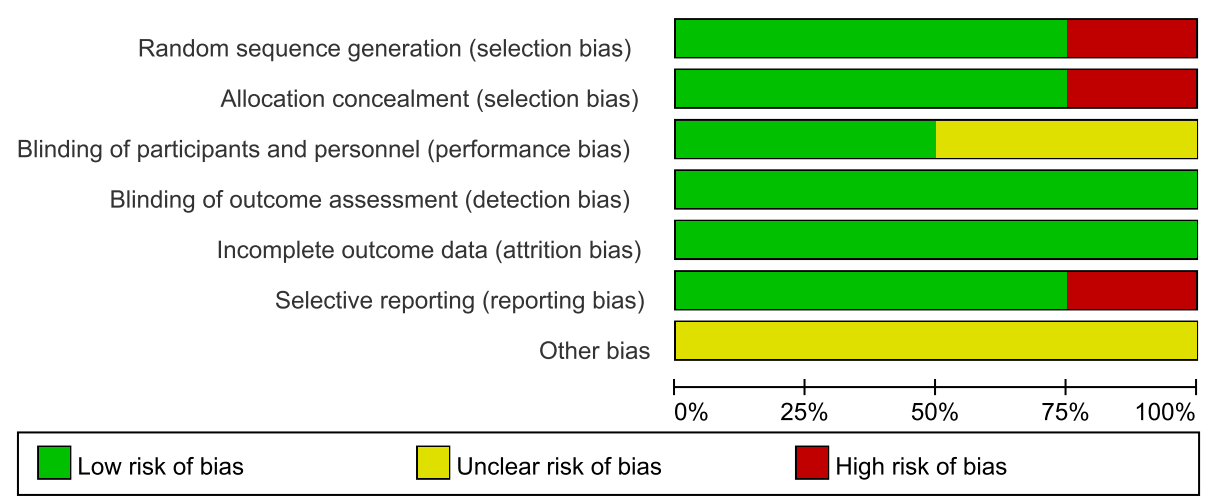

Fig. 2 Risk of bias graph for Randomized Controlled Trials (RCTs) 


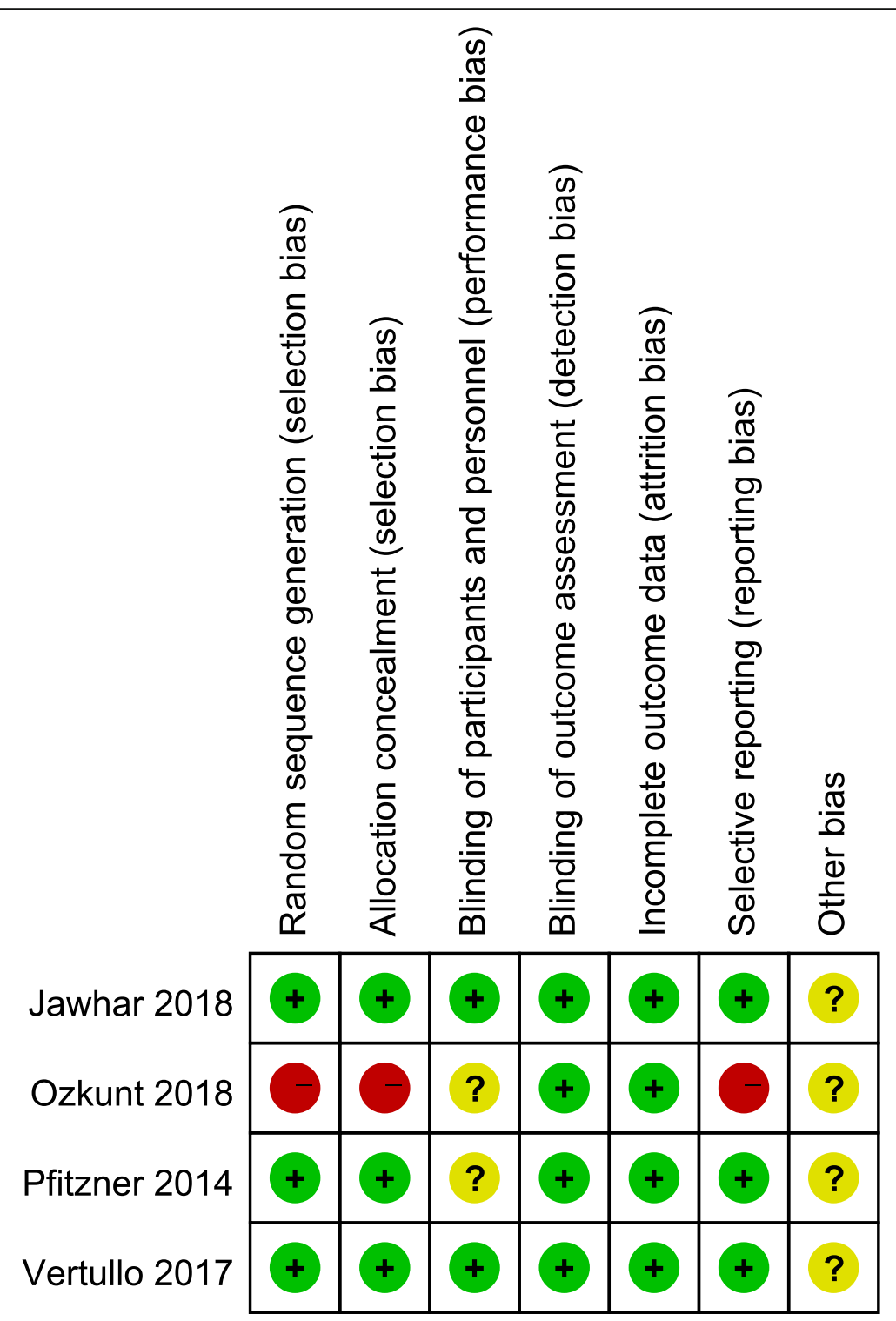

Fig. 3 Risk of bias summary for Randomized Controlled Trials (RCTs)

tables. Heterogeneity was quantified using $P$ and $I^{2}$. A fixed-effects model $\left(P>0.1\right.$ and $\left.I^{2}<50 \%\right)$ or randomeffects model $\left(P \leq 0.1\right.$ and $\left.I^{2} \geq 50 \%\right)$ was used to pool the data. The study-specific odds ratio (OR) with $95 \%$ confidence interval $(\mathrm{CI})$ was employed to determine the value of dichotomous data. The continuous data were summarized as mean difference (MD) with $95 \%$ CI using the MantelHaenszel method [26]. We used forest plots to graphically present the results of individual studies and the respective pooled estimate of effect size. Statistical significance was set at a $P<0.05$. Publication bias was assessed using a funnel plot of the outcome measurement recorded in the largest number of clinical trials. Review Manager (RevMan, version 5.4) for Windows 10 and the Cochrane collaboration was utilized to perform all the statistical analyses.

\section{Results}

\section{Search Results}

A total of 391 studies were identified. Upon reviewing of the titles, abstracts, and full articles, the unrelated articles were excluded. A total of 7 studies (4 RCTs and 3

Table 2 Quality assessment of 3 non-randomized controlled trials

\begin{tabular}{lllll}
\hline Studies & \multicolumn{2}{l}{ Newcastle-Ottawa Scale } & Quality \\
\cline { 2 - 4 } & Selection & Comparability & Exposure & \\
\hline Touzopoulos 2019 [18] & $* * *$ & $* *$ & $* * *$ & High \\
Herndon 2019 [19] & $* * *$ & $* *$ & $* * *$ & High \\
Dincel 2020 [20] & $* * *$ & $* *$ & $* * *$ & High \\
\hline
\end{tabular}

**, scored 2 points; ***, scored three points 


\begin{tabular}{|c|c|c|c|c|c|c|c|c|c|c|c|}
\hline \multirow[b]{2}{*}{ Study or Subgroup } & \multicolumn{3}{|c|}{ Tourniquet } & \multicolumn{3}{|c|}{ No tourniquet } & \multicolumn{2}{|r|}{ Mean Difference } & \multirow{2}{*}{\multicolumn{3}{|c|}{$\begin{array}{l}\text { Mean Difference } \\
\text { IV. Fixed, } 95 \% \text { CI }\end{array}$}} \\
\hline & Mean & SD & Total & Mean & SD & Total & Weight & IV, Fixed, $95 \% \mathrm{Cl}$ & & & \\
\hline Dincel 2020 & 2.35 & 0.24 & 74 & 2.33 & 0.25 & 96 & $78.4 \%$ & $0.02[-0.05,0.09]$ & & & \\
\hline Herndon 2019 & 2.55 & 1.88 & 70 & 2.5 & 1.43 & 70 & $1.4 \%$ & $0.05[-0.50,0.60]$ & & & \\
\hline Jawhar 2018 & 2.85 & 0.54 & 43 & 2.66 & 0.51 & 43 & $8.7 \%$ & $0.19[-0.03,0.41]$ & & & \\
\hline Ozkunt 2018 & 2.5 & 0.39 & 24 & 2.27 & 0.64 & 25 & $4.9 \%$ & $0.23[-0.07,0.53]$ & & & \\
\hline Pfitzner 2014 & 2.37 & 0 & 45 & 2.17 & 0 & 45 & & Not estimable & & & \\
\hline Touzopoulos 2019 & 1.75 & 0.94 & 50 & 1.55 & 0.76 & 50 & $3.8 \%$ & $0.20[-0.14,0.54]$ & & & \\
\hline Vertullo 2017 & 2.78 & 0.62 & 20 & 2.82 & 0.68 & 20 & $2.6 \%$ & $-0.04[-0.44,0.36]$ & & & \\
\hline Total $(95 \% \mathrm{Cl})$ & & & 326 & & & 349 & $100.0 \%$ & $0.05[-0.01,0.12]$ & & & \\
\hline $\begin{array}{l}\text { Heterogeneity: } \mathrm{Chi}^{2}= \\
\text { Test for overall effect: }\end{array}$ & $\begin{array}{l}4.54, \mathrm{df}= \\
Z=1.52\end{array}$ & $\begin{array}{l}=5(P= \\
(P=0 .\end{array}$ & $\begin{array}{l}=0.47) \\
.13)\end{array}$ & $I^{2}=0 \%$ & & & & & -0.5 & $\begin{array}{l}-0.25 \quad 0 \\
\text { Tourniquet }\end{array}$ & $\begin{array}{c}0.25 \\
\text { No tourniquet }\end{array}$ \\
\hline
\end{tabular}

non-RCTs) involving 675 knees were eligible and included for the final meta-analysis (Fig. 1) [5, 14, 15, 1720]. In one study, gender was omitted; in the other 6 studies, there were 258 male and 368 female patients, with their mean ages ranging from 65 years to 71 years. Body mass index (BMI) (range, 26 to 32) was reported in 5 studies. The participants' demographics are shown in Table 1.

\section{Risk of Bias Assessment}

All the RCTs provided clear inclusion and exclusion criteria, which suggested that methodologically randomization was used. Randomization algorithm was generated by computer in 2 studies, sealed envelopes were used in 1 study, and the order of admission to the hospital was used in 1 study. The surgeons were blinded in 2 studies. Clearly selective outcomes were reported in 6 studies. The outcome assessments were blinded in all RCTs. The results are summarized in Figs. 2 and 3. The NewcastleOttawa Scale, including selection, comparability, and exposure, was used to assess the retrospective studies. All the 3 studies showed good patient selection, unrelated variable control, and result reporting. Since all tourniquet and non-tourniquet groups were controlled in the hospital, they only got 3 stars (points) at the first part. The results are listed in Table 2.

\section{Meta-analysis}

Cement penetration in the tourniquet and nontourniquet groups was compared in 7 studies, and the data were expressed as mean \pm standard deviation in 6 studies. To make it comparable, we calculated the mean values of the depth of cement penetration (range, $1.55-2.85 \mathrm{~mm}$ ). There was no significant statistical difference between the tourniquet and nontourniquet groups $(P=0.13 ; \mathrm{MD}=0.05 ; 95 \% \mathrm{CI},-0.01$ to 0.12; Fig. 4).

Surgical time was recorded in 2 studies, but the difference between the 2 studies was evident due to the different surgeons and surgical skills. However, the pooled data were still comparable, and showed no statistically significant difference between the tourniquet and nontourniquet groups $(P=0.79 ; \mathrm{MD}=2.21 ; 95 \% \mathrm{CI},-13.75$ to 18.18) (Fig. 5).

Postoperative drainage or estimated total blood loss was reported in 3 studies, and transfusion was recorded in 2 studies. There were no statistically significant differences between the tourniquet and non-tourniquet groups in terms of blood loss or transfusion $(P=0.36$; $\mathrm{MD}=-142.32 ; 95 \% \mathrm{CI},-165.15$ to 449.80 ; and $\mathrm{OR}=$ $0.74 ; 95 \% \mathrm{CI}, 0.24$ to $2.31 ; P=0.60$ ) (Figs. 6 and 7 ).

The KSS was used to assess the range of motion and knee function in 2 studies. Although the scores of the non-tourniquet groups had a cumulative increase of 10.69 points, the pooled data showed no statistically

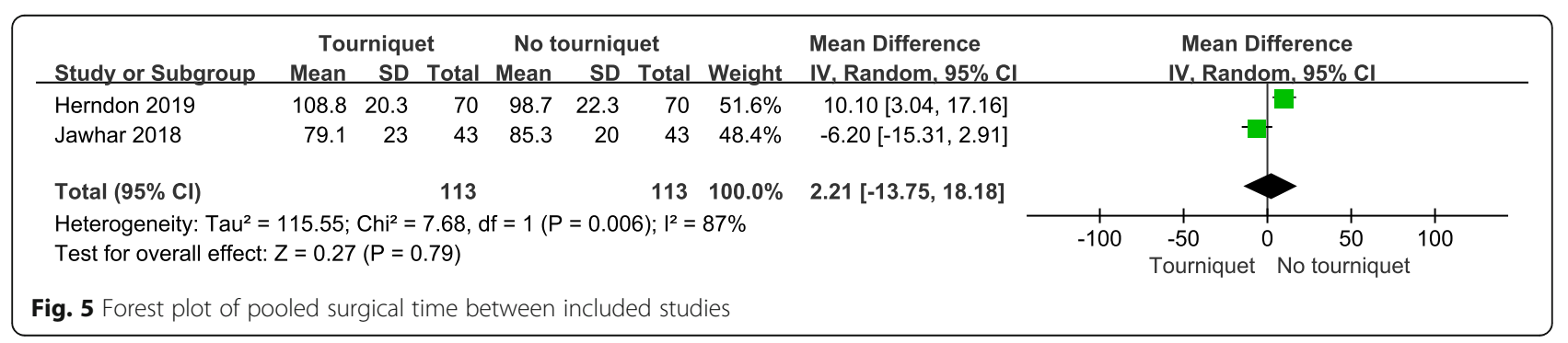




\begin{tabular}{|c|c|c|c|c|c|c|c|c|c|c|c|}
\hline \multirow[b]{2}{*}{ Study or Subgroup } & \multicolumn{3}{|c|}{ Tourniquet } & \multicolumn{3}{|c|}{ No tourniquet } & & \multirow{2}{*}{$\begin{array}{l}\text { Mean Difference } \\
\text { IV. Random. } 95 \% \mathrm{CI}\end{array}$} & \multirow{2}{*}{\multicolumn{3}{|c|}{$\begin{array}{c}\text { Mean Difference } \\
\text { IV. Random. } 95 \% \mathrm{Cl}\end{array}$}} \\
\hline & Mean & SD & Total & Mean & SD & Total & Weight & & & & \\
\hline Herndon 2019 & 100 & 0 & 70 & 154.7 & 92.8 & 70 & & Not estimable & & & \\
\hline Ozkunt 2018 & 245 & 24.6 & 24 & 258.76 & 32.4 & 25 & $50.3 \%$ & $-13.76[-29.83,2.31]$ & & T & \\
\hline Pfitzner 2014 & 900 & 89 & 45 & 600 & 133 & 45 & $49.7 \%$ & $300.00[253.24,346.76]$ & & ㄴ. & \\
\hline Total $(95 \% \mathrm{Cl})$ & & & 139 & & & 140 & $100.0 \%$ & $142.32[-165.15,449.80]$ & & & \\
\hline $\begin{array}{l}\text { Heterogeneity: } \text { Tau }^{2} \\
\text { Test for overall effect }\end{array}$ & $\begin{array}{l}48904.5 \\
Z=0.91\end{array}$ & $\begin{array}{l}1 ; \mathrm{Chi}^{2} \\
(\mathrm{P}=0\end{array}$ & $\begin{array}{l}=154 . \\
36)\end{array}$ & $71, \mathrm{df}=$ & $1(P<C$ & .00001 & 1); $1^{2}=99$ & & -1000 & $\begin{array}{lll}-500 & 0 & 500\end{array}$ & 1000 \\
\hline
\end{tabular}

Fig. 6 Forest plot of pooled Blood loss among included studies

significant difference between the tourniquet and nontourniquet groups $(P=0.21 ; \mathrm{MD}=-10.69 ; 95 \% \mathrm{CI}$, -27.38 to 6.00 ) (Fig. 8).

The VAS was used to evaluate postoperative knee pain in 3 studies (225 patients). The VAS of the nontourniquet group was 0.89 points, which was higher than that of the tourniquet group but the difference was not statistically significant $(P=0.25 ; \mathrm{MD}=0.89 ; 95 \% \mathrm{CI}$, -0.61 to 2.39) (Fig. 9).

Publication bias was assessed by creating a funnel plot, which demonstrated the relationship between the sample size of the studies and the precision in the estimation of the treatment effect. The result showed no substantial evidence of publication bias in cement penetration (Fig. 10).

\section{Discussion}

The most important finding of this meta-analysis was that both the tourniquet-assisted and non-tourniquetassisted TKAs yielded very similar results in terms of cement penetration, surgical time, blood loss, transfusion, KSS, and VAS.

The implant stability is intimately associated with the depth of cement penetration [27, 28]. For cement to reach the first transverse trabeculae, $2-3 \mathrm{~mm}$ penetration was required [8]. Walker et al. [28] suggested that the optimal depth of cement penetration is 3 to $4 \mathrm{~mm}$ for maximal cement-bone interface fixation. In our study, however, the mean cement penetration depth ranged from $1.55 \mathrm{~mm}$ to $2.85 \mathrm{~mm}$, which might vary with operative skills of different surgeons.

So far, tourniquet use in TKA remains controversial. Touzopoulos et al. [18] demonstrated the average penetration at all levels was less than $2 \mathrm{~mm}$ in the tourniquet-assisted TKA, whereas the penetration in the non-tourniquet-assisted TKA was $1.2 \mathrm{~mm}$ cumulatively. In a randomized, prospective clinical trial, Pfitzner et al. [5] evaluated the cement mantle of the tibial component in primary TKA and found the use of a tourniquet increased the tibial cement mantle thickness by1.2 $\mathrm{mm}$. Hofmann et al. [29] identified a $2.69 \mathrm{~mm}$ overall depth of penetration in 109 patients and their mid-term follow-up revealed excellent durability. Ozkunt et al. [15] found an average of $2.35 \mathrm{~mm}$ penetration, and the use of tourniquet had no effect on cement penetration. Furthermore, some surgeons radiosterometrically compared the short-term effect on implant stability and failed to find significant difference in terms of implant stability between the two groups [16, 30, 31].

Reducing bleeding is one of the reasons for using a tourniquet in TKA. In a recent systematic review involving 25 RCTs, Moher et al. [32] showed the use of tourniquet significantly decreased intraoperative blood loss but might not reduce the total blood loss. Li et al. [33] retrospectively compared the tourniquet-assisted TKAs to the non-tourniquet-assisted ones, and found no difference in perioperative blood loss or postoperative blood transfusion. Pfitzner et al. [5] found that blood loss was more in tourniquet-assisted TKAs.

\begin{tabular}{|c|c|c|c|c|c|c|c|c|c|c|}
\hline Study or Subgroup & \multicolumn{2}{|c|}{ Tourniquet } & \multicolumn{2}{|c|}{ No tourniquet } & Weight & $\begin{array}{c}\text { Odds Ratio } \\
\text { M-H, Fixed, 95\% Cl }\end{array}$ & \multicolumn{4}{|c|}{$\begin{array}{c}\text { Odds Ratio } \\
\text { M-H, Fixed, 95\% Cl }\end{array}$} \\
\hline Jawhar 2018 & 1 & 43 & 4 & 43 & $55.7 \%$ & $0.23[0.02,2.17]$ & & $\sqrt{2}$ & $\frac{1}{4}$ & \\
\hline Ozkunt 2018 & 5 & 24 & 4 & 25 & $44.3 \%$ & $1.38[0.32,5.91]$ & & & $f-$ & \\
\hline Total $(95 \% \mathrm{Cl})$ & & 67 & & 68 & $100.0 \%$ & $0.74[0.24,2.31]$ & & & & \\
\hline Total events & 6 & & 8 & & & & & & & \\
\hline $\begin{array}{l}\text { Heterogeneity: } \mathrm{Chi}^{2}= \\
\text { Test for overall effect }\end{array}$ & $\begin{array}{l}.74, \mathrm{df}=1 \\
z=0.52(F\end{array}$ & $\begin{array}{l}1(P=0 \\
=0.60\end{array}$ & $\begin{array}{l}\text {.19); }\left.\right|^{2}= \\
0)\end{array}$ & & & & 0.01 & $\begin{array}{l}0.1 \\
\text { Tourniquet }\end{array}$ & $\begin{array}{c}10 \\
\text { No tourniquet }\end{array}$ & 100 \\
\hline
\end{tabular}




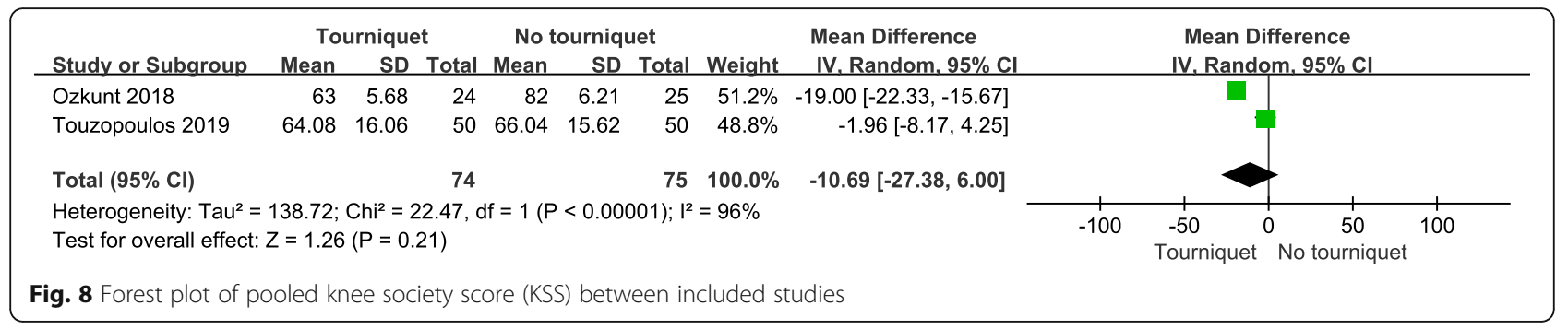

In the past, the application of a tourniquet in TKA was also believed to be able to shorten surgical time. In a prior meta-analysis involving 13 RCTs (859 patients), Yi et al. [34] demonstrated that tourniquet use could reduce the surgical time. Mutlu et al. [35] reported similar results in a retrospective cohort study. However, different viewpoints have been proposed in more studies. In a randomized study of 70 patients, Ejaz et al. [36] showed the tourniquet group and the non-tourniquet group took similar surgical time $(71 \pm 4.5 \mathrm{~min}$ vs. $70 \pm 5.3 \mathrm{~min})$. Herndon et al. [19] reported a longer surgical time in the tourniquet group (109 $\mathrm{min}$ ) than in the nontourniquet group $(99 \mathrm{~min})$. In the present study, we did not find a significant difference because only limited studies were included.

In a prospective, randomized study, Zhao et al. [37] showed that the KSS was significantly better in the nontourniquet group 3 weeks after surgery but no significant difference was found after 3 months. In another prospective randomized study, Ozkunt et al. [15] did not observe any statistically significant differences in preoperative KSS between the long-duration tourniquet group, shortduration tourniquet group, and non-tourniquet group. However, a significantly worse postoperative KSS was found in the long-duration tourniquet group. Furthermore, in a recent comparative study, Touzopoulos et al. [18] found no significant difference in KSS at the final follow-up. From those limited studies, we are led to conclude that there existed no difference between tourniquetassisted and non-tourniquet-assisted TKAs.
Olivecrona et al. [38] showed that long tourniquet time (over $100 \mathrm{~min}$ ) raised the risks of complications caused by oxygen deprivation of the soft tissues, ischemia-reperfusion injury, local inflammation, muscle injuries, and knee pain. Oxygen-free radicals and inflammatory factors (neutrophils, tumor necrosis factor $\alpha$, and interleukin 8) are also important contributors [39]. Excessive use of a tourniquet and increased pressure applied lead to swelling and congestion of the bone compartment and might lead to rhabdomyolysis [40]. Ejaz et al. [36] found that complications were less in non-tourniquet-assisted TKAs.

Jawhar et al. [17] performed 86 primary TKAs. They found deep vein thrombosis in one patient and did one revision surgery due to surgical site infection in the tourniquet group. In the non-tourniquet group, one patient had a delayed wound healing. There was no significant difference between the two groups in the complications.

This study has some limitations. First, the low level of evidence of the 3 non-RCTs might lead to statistical bias and involve other confounding variables. Second, the publication bias might affect the outcomes. Third, the limited studies and different standards on cement penetration rendered the data less comparable. Finally, the differences in surgical techniques, bone densities, and cement used might impact the final results. Future high-quality RCTs are warranted to illustrate the exact effect of tourniquet on TKA outcomes.

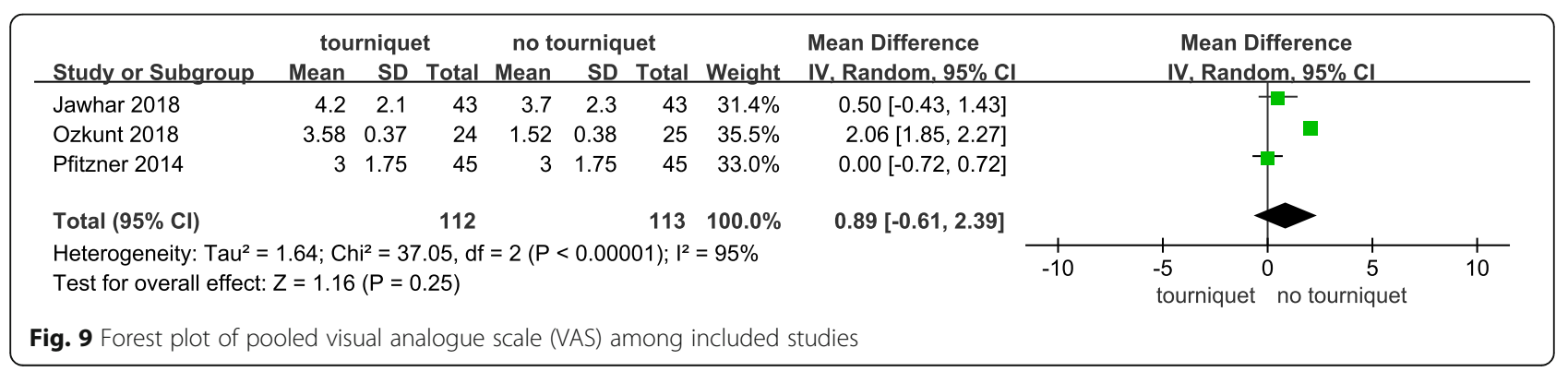




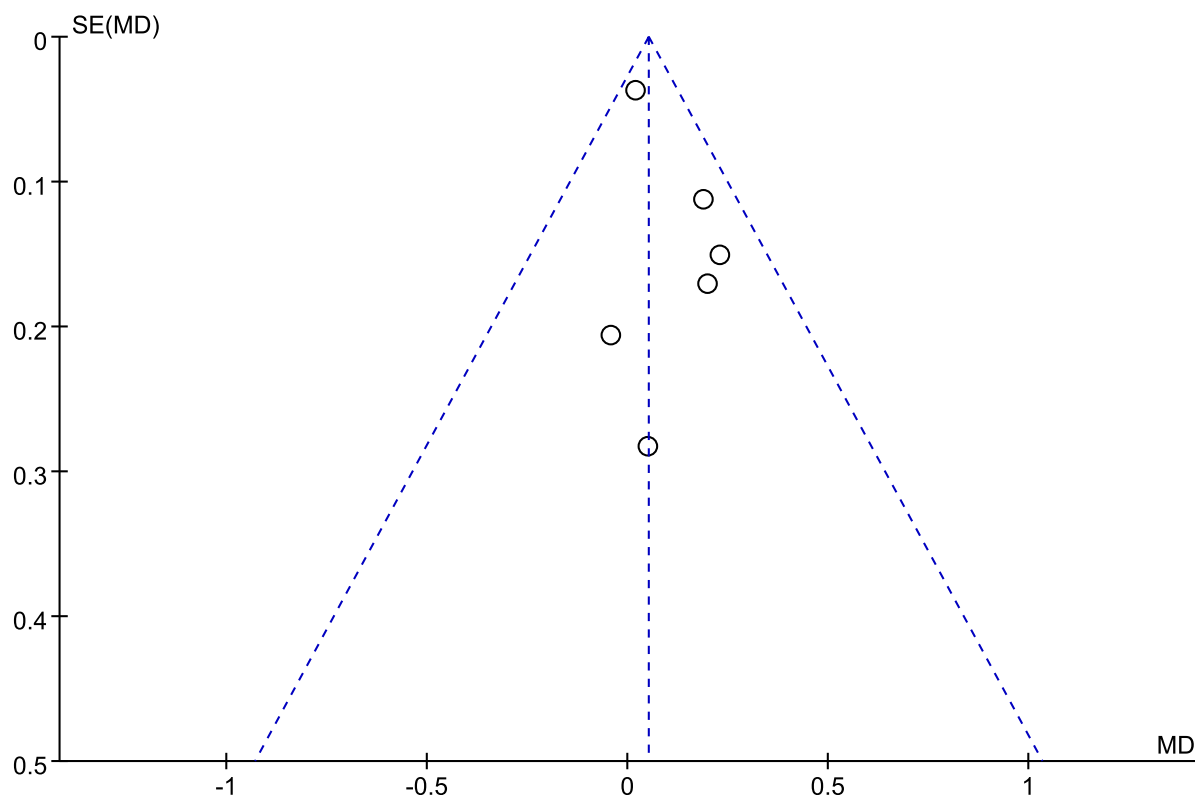

Fig. 10 Funnel plot demonstrating a minimal publication bias of cement penetration

\section{Conclusions}

Tourniquet application may not improve cement penetration in TKA and may not offer benefits for reducing blood loss, easing knee pain or improving the knee function.

\section{Abbreviations}

ERAS: Enhanced recovery after surgery; TKA: Total knee arthroplasty; RCTs: Randomized controlled trials; KSS: Knee society score; VAS: Visual analogue scale; OA: Osteoarthritis; PRISMA: Preferred Reporting Items for Systematic Reviews and Meta-Analyses guidelines; NOS: Newcastle-Ottawa Quality Assessment Scale; OR: Odds Ratio; MD: Mean difference;

$\mathrm{Cl}$ : Confidence intervals

\section{Acknowledgements}

Not applicable.

\section{Authors' contributions}

JP Wang and SX Yao collected the data and wrote the manuscript. WJ Zhang provided the statistical support and revised the manuscript. JB Ma developed the idea and revised the manuscript. All authors read and approved the final manuscript.

\section{Funding}

This study was supported by a grant from the National Natural Science Foundation of China (No. 81601937).

\section{Availability of data and materials}

The datasets used or analyzed during the current study are available from the corresponding author on reasonable request.

\section{Declarations}

Ethics approval and consent to participate

Not applicable.

\section{Consent for publication}

Not applicable.

\section{Competing interests}

Jianbing Ma is a member of the Editorial Board of Arthroplasty and other authors declare that they have no competing interests. All authors were not involved in the journal's review of or decisions related to, this manuscript.

Received: 9 February 2021 Accepted: 16 June 2021

Published online: 04 August 2021

\section{References}

1. Carr AJ, Robertsson O, Graves S, Price AJ, Arden NK, Judge A, Beard DJ. Knee replacement. Lancet. 2012;379:1331-40.

2. National Joint Registry. 14th annual report. National Joint Registry for England, Wales, Northern Ireland and Isle of Man. 2017 http://www. njrreports.org.uk/Portals/0/PDFdownloads/NJR\%20. th\%20Annual\%20Report\%202017.pdf (accessed 21 Apr, 2018).

3. Gu S, Kuriyama S, Nakamura S, Nishitani K, Ito H, Matsuda S. Underhang of the tibial component increases tibial bone resorption after total knee arthroplasty. Knee Surg Sports Traumatol Arthrosc. 2019;27(4):1270.

4. Westerman RW. Can tibial cementation be enhanced in knee arthroplasty surgery? J Knee Surg. 2016;29(5):391.

5. Pfitzner T, von Roth P, Voerkelius N, Mayr H, Perka C, Hube R. Influence of the tourniquet on tibial cement mantle thickness in primary total knee arthroplasty. Knee surgery sports traumatology arthroscopy: official journal of the ESSKA. 2016;24(1):96-101. doi:https://doi.org/10.1007/s00167014-3341-6.

6. Ritter MA, Keating EM, Sueyoshi T, Davis KE, Barrington JW, Emerson RH Twenty-five-years and greater, results after nonmodular cemented total knee arthroplasty. J Arthroplasty. 2016;31(10):2199.

7. Insall J, Scott WN, Ranawat CS. The total condylar knee prosthesis. A report of two hundred and twenty cases. J Bone Joint Surg Am. 1979;61(2):173.

8. Lutz MJ, Pincus PF, Whitehouse SL, Halliday BR. The effect of cement gun and cement syringe use on the tibial cement mantle in total knee arthroplasty. J Arthroplasty. 2009;24(3):461.

9. Peters $\mathrm{CL}$, Craig MA, Mohr RA, Bachus KN. Tibial component fixation with cement: full- versus surface-cementation techniques. Clin Orthop Relat Res. 2003;409:158.

10. van Loon CJ, de Waal Malefijt MC, Buma P, Verdonschot N, Veth RP. Femoral bone loss in total knee arthroplasty. Areview Acta Orthop Belg. 1999;65(2):154.

11. Tai TW, Lin CJ, Jou IM, Chang CW, Lai KA, Yang CY. Tourniquet use in total knee arthroplasty: a meta-analysis. Knee Surg Sports Traumatol Arthrosc. 2011;7(19):1121-30. 
12. Majkowski RS, Bannister GC, Miles AW. The effect of bleeding on the cement-bone interface. An experimental study i. 2009;299:293.

13. Radin EL, Rubin CT, Thrasher EL, Lanyon LE, Crugnola AM, Schiller AS, Paul $\mathrm{IL}$, Rose RM. Changes in the bone-cement interface after total hip replacement. An in vivo animal study. J Bone Joint Surg Am. 1982;64(8): 1188.

14. Vertullo CJ, Nagarajan M. Is cement penetration in TKR reduced by not using a tourniquet during cementation? A single blinded, randomized trial. Journal of Orthopaedic Surgery. 2017;25(1). doi:https://doi.org/10.1177/23 09499016684323.

15. Ozkunt O, Sariyilmaz K, Gemalmaz HC, Dikici F. The effect of tourniquet usage on cement penetration in total knee arthroplasty: A prospective randomized study of 3 methods. Medicine. 2018;97(4):e9668. doi:https://doi. org/10.1097/md.0000000000009668. PubMed PMID: 29369184; PubMed Central PMCID: PMCPMC5794368. Epub 2018/01/26.

16. Molt M, Harsten A, Toksvig-Larsen $\mathrm{S}$. The effect of tourniquet use on fixation quality in cemented total knee arthroplasty a prospective randomized clinical controlled RSA trial. Knee. 2014;21(2):396-401. doi:https://doi.org/10.1 016/j.knee.2013.10.008

17. Jawhar A, Stetzelberger V, Kollowa K, Obertacke U. Tourniquet application does not affect the periprosthetic bone cement penetration in total knee arthroplasty. Knee Surg Sports Traumatol Arthrosc. 2019;27(7):2071-81. doi: https://doi.org/10.1007/s00167-018-5330-7. PubMed PMID: 30539303. Epub 2018/12/13.

18. Touzopoulos P, Ververidis A, Mpogiatzis C, Chatzigiannakis A, Drosos Gl. The use of tourniquet may influence the cement mantle thickness under the tibial implant during total knee arthroplasty. Eur J Orthop Surg Traumatol. 2019;29(4):869-75. doi:https://doi.org/10.1007/s00590-019-02369-8. PubMed PMID: 30617921. Epub 2019/01/09.

19. Herndon CL, Grosso MJ, Sarpong NO, Shah RP, Geller JA, Cooper HJ. Tibial cement mantle thickness is not affected by tourniquetless total knee arthroplasty when performed with tranexamic acid. Knee Surg Sports Traumatol Arthrosc. 2020;28(5):1526-31. doi:https://doi.org/10.1007/s00167019-05559-3. PubMed PMID: 31190247. Epub 2019/06/14.

20. Dincel YM, Sarı A, Çetin M, Günaydın B, Agca E, Dogan AH, et al. The Effect of Tranexamic Acid and Tourniquet Use on Tibial Cement Penetration in Primary Total Knee Arthroplasties. Arthroplast Today. 2020;6(3):422-6. doi: https://doi.org/10.1016/j.artd.2020.04.010. PubMed PMID: 32613048; PubMed Central PMCID: PMCPMC7316986. Epub 2020/07/03.

21. Sapega AA, Heppenstall RB, Chance B, Park YS, Sokolow D. Optimizing tourniquet application and release times in extremity surgery: a biochemical and ultrastructural study. J Bone Joint Surg Am. 1985;67(2):303.

22. Worland RL, Arredondo J, Angles F, Lopez-Jimenez F, Jessup DE. Thigh pain following tourniquet application in simultaneous bilateral total knee replacement arthroplasty. J Arthroplasty. 1997;12(8):848.

23. Moher D, Liberati A, Tetzlaff J, Altman DG. Preferred reporting items for systematic reviews and meta-analyses: the PRISMA statement. PLoS Med. 2009;6:e1000097. doi:https://doi.org/10.1371/journal.pmed.1000097. doi.

24. Higgins JPT, Green S. Cochrane handbook for systematic reviews of interventions version 5.1.0. In: The cochrane collaboration; 2011. http:// www.handbook.cochrane.org. Accessed 15 Nov 2016.

25. Ga Wells BS, O'Connell D, Peterson J, Welch V, Losos M. NewcastleOttawa quality assessment scale. Otawwa Hosp. Res. Inst; 2014.

26. Mantel N, Haenszel W. Statistical aspects of the analysis of data from retrospective studies of disease. J Natl Cancer Inst. 1959;22(4):719-48. Epub 1959/04/01. PubMed PMID: 13655060.

27. Scott CE, Biant LC. The role of the design of tibial components and stems in knee replacement. J Bone Joint Surg Br. 2012;94(8):1009.

28. Walker PS, Soudry M, Ewald FC, McVickar H. Control of cement penetration in total knee arthroplasty. Clin Orthop Relat Res. 1984;185:155.

29. Hofmann AA, Goldberg TD, Tanner AM, Cook TM. Surface cementation of stemmed tibial components in primary total knee arthroplasty: minimum 5year follow-up. J Arthroplasty. 2006;21(3):353

30. Ledin $\mathrm{H}$, Aspenberg $\mathrm{P}$, Good L. Tourniquet use in total knee replacement does not improve fixation, but appears to reduce final range of motion. Acta Orthop. 2012;83(5):499-503. doi:https://doi.org/10.3109/17453674.2012. 727078

31. Ejaz A, Laursen AC, Jakobsen T, Rasmussen S, Nielsen PT, Laursen MB. Absence of a Tourniquet Does Not Affect Fixation of Cemented TKA: A Randomized RSA Study of 70 Patients. J Arthroplasty. 2015;30(12):2128-32. doi:https://doi.org/10.1016/j.arth.2015.05.058.
32. Liu Y, Si H, Zeng Y, Li M, Xie H, Shen B. More pain and slower functional recovery when a tourniquet is used during total knee arthroplasty. Knee Surg Sports Traumatol Arthrosc. 2020;28(6):1842-60. Epub 2019/07/11. doi: https://doi.org/10.1007/s00167-019-05617-w. PubMed PMID: 31289914.

33. Li Y, Lu M, Tian H, Li ZJ, Zhang K. Effect of different tourniquet releasing strategy on blood loss in total knee arthroplasty. Zhonghua yi xue za zhi. 2017;97(41):3219-24. doi:https://doi.org/10.3760/cma.j.issn.0376-2491.201 7.41 .005 .

34. Yi S, Tan J, Chen $\mathrm{C}$, Chen $\mathrm{H}$, Huang W. The use of pneumatic tourniquet in total knee arthroplasty: a meta-analysis. Arch Orthop Trauma Surg. 2014; 134(10):1469-76. Epub 2014/08/19. doi: https://doi.org/10.1007/s00402-014-2 056-y. PubMed PMID: 25128975.

35. Mutlu S, Guler O, Mutlu H, Karaman O, Duymus TM, Parmaksizoglu AS. Tourniquet use during total knee arthroplasty does not offer significant benefit: A retrospective cohort study. Int J Surg. 2015;18:123-7. doi:https:// doi.org/10.1016/j.jisu.2015.04.054. PubMed PMID: 25917205. Epub 2015/04/ 29.

36. Ejaz A, Laursen AC, Kappel A, Laursen MB, Jakobsen T, Rasmussen S, Nielsen PT. Faster recovery without the use of a tourniquet in total knee arthroplasty. Acta Orthop. 2014;85(4):422-6. doi:https://doi.org/10.3109/174 53674.2014.931197.

37. Zhao HY, Yeersheng R, Kang XW, Xia YY, Kang PD, Wang WJ. The effect of tourniquet uses on total blood loss, early function, and pain after primary total knee arthroplasty a prospective, randomized controlled trial. Bone joint research. 2020;9(6):322-32. doi:https://doi.org/10.1302/2046-3758.96.BJR-201 9-0180.R3. PubMed PMID: CN-02144638.

38. Olivecrona C, Lapidus LJ, Benson L, Blomfeldt R. Tourniquet time affects postoperative complications after knee arthroplasty. Int Orthop. 2013;37(5): 827-32.

39. GILLANI S, CAO J, SUZUKI T, Hak DJ. The effect of ischemia reperfusion injury on skeletal muscle. Injury. 2012;43(6):670-5.

40. MURATA I, NOZAKI R, OOI K, Ohtake K, Kimura S, Ueda H, Nakano G, Sonoda $K$, Inoue $Y$, Uchida $H$, Kanamoto I, Morimoto $Y$, Kobayashi J. Nitrite reduces ischemia/reperfusion-induced muscle damage and improves survival rates in rat crush injury model. J Trauma Acute Care Surg. 2012;72(6):1548-54.

\section{Publisher's Note}

Springer Nature remains neutral with regard to jurisdictional claims in published maps and institutional affiliations.

Ready to submit your research? Choose BMC and benefit from:

- fast, convenient online submission

- thorough peer review by experienced researchers in your field

- rapid publication on acceptance

- support for research data, including large and complex data types

- gold Open Access which fosters wider collaboration and increased citations

- maximum visibility for your research: over $100 \mathrm{M}$ website views per year

At BMC, research is always in progress.

Learn more biomedcentral.com/submissions 